\title{
APRENDIZAGEM PROFISSIONAL: POSSIBILIDADES E PERSPECTIVAS PARA ADOLESCENTES E JOVENS DAS CLASSES POPULARES
}

\author{
Matilde Dias Martins Pupo, Sandra Terezinha Urbanetz \\ Instituto Federal de Educação, Ciência e Tecnologia do Paraná \\ DOI: 10.15628/rbept.2019.8212 \\ Artigo submetido em abr/2019 e aceito em dez/2019
}

\section{RESUMO:}

Pensar em educação profissional na sociedade brasileira é encarar a dualidade histórica existente desde os primórdios do processo educacional no Brasil, em que para os filhos da classe operária era fornecida uma educação para o trabalho braçal e para os filhos das elites uma educação propedêutica, voltada aos cursos superiores de graduação. Nesse contexto, a aprendizagem profissional se coloca como uma alternativa a esses adolescentes e jovens da classe operária que, além de estudar, precisam trabalhar, não podem esperar concluir o ensino superior para ir em busca de uma inserção no mundo do trabalho, pois as necessidades financeiras se sobrepõem. Este artigo apresenta aspectos dessa dualidade histórica, por meio de uma revisão bibliográfica, parte integrante de uma pesquisa de Mestrado Profissional realizada no período de janeiro de dois mil e dezoito a março de dois mil e dezenove. Apresenta-se as principais características do que se entende por Aprendizagem Profissional, as alterações ocorridas nesta modalidade no decorrer da história e que hoje, embora com algumas fragilidades, se coloca como alternativa a milhares de adolescentes e jovens pobres para uma inserção protegida no mundo do trabalho, garantindo-Ihes o acesso a direitos humanos previstos na Constituição Federal do Brasil.

Palavras-chave: Educação Profissional. Aprendizagem Profissional. Mundo do Trabalho.

\begin{abstract}
:
Abstract: To think about professional education in Brazilian society is to look at the historical duality that existed since the beginning of the educational process in Brazil, where for the children of the working class there was provided an education for the manual labor and for the children of the elites a propaedeutic education, undergraduate courses. In this context, vocational learning is an alternative to these working-class adolescents and young people who, in addition to studying, need to work, cannot expect to complete higher education in order to seek insertion in the world of work, since the needs overlap. This article presents aspects of this historical duality, through a bibliographical revision, an integral part of a research of Professional Masters held in the period from January of two thousand and eighteen to March of two thousand and nineteen. It also presents the main characteristics of what is understood by Professional Learning, the changes that have occurred in this modality throughout history and that today, although with some weaknesses, it places itself as an alternative to thousands of poor adolescents and young people for a
\end{abstract}


protected insertion in the world guaranteeing access to human rights under the Federal Constitution of Brazil.

Keywords: Professional education. Professional Learning. Labor market.

\section{INTRODUÇÃO}

A educação profissional no Brasil está relacionada a diversas mudanças históricas ocorridas no Brasil em meados do século XIX o que caracteriza uma trajetória marcada pela ascensão do capitalismo e as relações de trabalho, permeadas também por questões políticas, sendo a educação uma alternativa para consolidar as necessidades do mundo do trabalho e uma condição de capacitação e emancipação do cidadão/trabalhador.

A aprendizagem profissional é uma modalidade de educação profissional prevista na CLT em 1943, voltada principalmente para atender a demanda de um país em fase de industrialização, que precisava de trabalhadores qualificados, e também para regular o trabalho de adolescentes e jovens e lhes garantir alguns direitos.

Um avanço nesse processo ocorre com a promulgação da Lei 10.097/2000 e do decreto № 5.598/2005 que determinam que empresas de médio e grande porte são obrigadas a contratar aprendizes, num percentual de 5 a 15\%, de acordo com o total de trabalhadores, cujas funções demandem formação profissional. Outras alterações ocorreram também a partir dessas legislações e serão trabalhadas neste artigo, tendo como objetivo discutir a aprendizagem profissional enquanto uma alternativa aos adolescentes e jovens que precisam se inserir no mundo do trabalho para auxiliar financeiramente suas famílias. Trata-se de um público que não pode esperar o término de um curso superior para iniciar sua carreira profissional e muitas vezes inserem-se em trabalhos precários, informais, sem a garantia de direitos trabalhistas e outros.

A aprendizagem profissional também se apresenta como estratégia para a política de assistência social, em que são inseridos adolescentes e jovens atendidos nos CRAS (Centro de Referência de Assistência Social ${ }^{1}$ ) e nos CREAS (Centro de Referência Especializado de Assistência Social) ${ }^{2}$, principalmente os que se encontram em cumprimento de medidas socioeducativas em meio aberto, previstas no Estatuto da Criança e do Adolescente. Essas medidas "correspondem a sentenças judiciais proferidas por juízes das Varas da Infância e Adolescência (...) tais medidas podem ser de seis tipos: advertência, obrigação de reparar o dano, prestar serviços à comunidade, liberdade assistida e semiliberdade" (JOSVIAK, 2017, P. 71).

A discussão que este artigo pretende trazer à tona é da aprendizagem profissional enquanto possibilidade da garantia de direitos humanos a adolescentes e jovens oriundos das classes trabalhadoras, principalmente 0 direito da profissionalização e do acesso ao mundo do trabalho de maneira protegida. Para tanto o desenvolvimento foi organizado em tópicos, sendo que no tópico de numero

\footnotetext{
${ }^{1}$ Os CRAS são locais públicos, onde são ofertados serviços, benefícios e projetos de assistência social à população em situação de vulnerabilidade social. (Lei 12.435/2011).

${ }^{2}$ Os CREAS são locais públicos, voltados ao atendimento da população que se encontra em situação de risco social, ou que tiveram seus direitos violados (Lei 12.435/2011).
} 
dois é abordado um breve histórico da educação profissional brasileira, com ênfase na aprendizagem profissional. No tópico 2.1 apresenta-se a legislação nacional para os cursos de aprendizagem e no tópico 2.2 são demonstrados dados nacionais a respeito dos números de contratação de aprendizes em determinado período.

\title{
2 EDUCAÇÃO PROFISSIONAL NO BRASIL COM ENFOQUE NOS CURSOS DE APRENDIZAGEM
}

Diversos autores, como Moura (2010), apontam a criação do Colégio das Fábricas, por D. João $\mathrm{VI}$, em 1809, como a origem da educação profissional no Brasil. A partir de então, diversas outras iniciativas foram criadas, mas, conforme assinala o autor, com um viés assistencialista e cujo objetivo voltava-se mais para "amparar os órfãos e desvalidos da sorte, ou seja, de atender àqueles que não tinham condições sociais satisfatórias, para que não continuassem a praticar ações que estavam na contramão dos bons costumes" (MOURA, 2010, p. 61).

Com o início do processo de industrialização no Brasil, surge também a necessidade de pessoas mais capacitadas para atender a essa demanda e segundo Moura (2010, p. 62) "modifica-se a preocupação mais nitidamente assistencialista" que existia até então, para a preparação de mão de obra que atendesse essa necessidade, e desta forma, "a formação profissional passou a ser atribuição do Ministério da Agricultura, Indústria e Comércio".

Segundo Kuenzer (2000), o Estado assume a responsabilidade pela formação profissional em 1909, com a criação de escolas de artes e ofícios em vários estados brasileiros. Entretanto, essas escolas tinham muito mais um caráter moralizador do que propriamente para atender as necessidades da industrialização, ainda incipiente no Brasil. Kuenzer (2000, p. 27) afirma ainda que:

\begin{abstract}
A formação de trabalhadores e cidadãos no Brasil constitui-se historicamente a partir da categoria dualidade estrutural, uma vez que havia uma nítida demarcação da trajetória educacional dos que iriam desempenhar as funções intelectuais ou instrumentais, em uma sociedade cujo desenvolvimento das forças produtivas delimitava claramente a divisão entre capital e trabalho traduzida no taylorismo-fordismo como ruptura entre as atividades de planejamento e supervisão por um lado, e de execução por outro.
\end{abstract}

Em 1942, entra em vigor uma série de leis conhecidas como "Reforma Capanema", ou Leis Orgânicas do Ensino, que reformulam o ensino brasileiro, embora a dualidade persista, conforme aponta Kuenzer (2000, p. 28):

A dualidade estrutural, portanto, configura-se como a grande categoria explicativa da constituição do Ensino Médio e profissional no Brasil, legitimando a existência de dois caminhos bem diferenciados a partir das funções essenciais do mundo da produção econômica: um, para os que serão preparados pela escola para exercer suas funções de dirigentes; outro, para os que, com poucos anos de escolaridade, serão preparados para o mundo do trabalho em cursos específicos de formação profissional, na rede pública ou privada. 
Segundo Moura (2007, p. 9) "apesar dessa diferenciação, é nesse contexto que surge pela primeira vez uma possibilidade de aproximação entre o ramo secundário propedêutico (o colegial, com suas variantes científico e clássico) e os cursos profissionalizantes de nível médio, por meio de exames de adaptação".

No mesmo ano de implantação da Reforma Capanema foi criado o Serviço Nacional de Aprendizagem Industrial (SENAI) e em 1946 foi criado o Serviço Nacional de Aprendizagem Comercial (SENAC), iniciativas que, de acordo com Moura (2007, p. 9):

Revelam a opção governamental de repassar à iniciativa privada a tarefa de preparar "mão-de-obra" para o mundo produtivo. Assim, a partir dessa lógica, o ensino secundário e o normal formariam as elites condutoras do país e o ensino profissional formaria adequadamente os filhos de operários para as artes e os ofícios. Portanto, ratifica-se o caráter dualista da educação e a sua função reprodutora da estrutura social.

Para Manfredi (2016, p. 144) "O SENAI, desde sua fundação, representa a maior rede de educação profissional formadora de força de trabalho para os diferentes setores empresariais, notadamente para as empresas do setor industrial".

No dia $1^{\circ}$ de maio de 1943 foi publicado o Decreto-Lei $n .0$ 5.452, conhecido como Consolidação das Leis do Trabalho (CLT), a qual dedica todo o capítulo IV, ou seja, dos artigos 402 ao 441, para tratar "Da Proteção do Trabalho do Menor", estabelecendo a duração do trabalho; da admissão em emprego e da carteira de trabalho e previdência social; dos deveres dos responsáveis legais de menores e dos empregadores da aprendizagem; das penalidades quando não cumpridas as exigências estipuladas pela legislação.

No decorrer do processo histórico o trabalho de menores de 18 anos foi adquirindo maior atenção e a elaboração de novas leis surgiu para regulamentar a contratação desse público como, por exemplo, a Constituição Federal de 1988 que em seu art. $7 .^{\circ}$ inciso XXXIII prevê a "proibição de trabalho noturno, perigoso ou insalubre aos menores de dezoito e de qualquer trabalho a menores de quatorze anos, salvo na condição de aprendiz". Por meio da Emenda Constitucional n.. 20/1998 esse inciso foi alterado para "proibição de trabalho noturno, perigoso ou insalubre a menores de dezoito e de qualquer trabalho a menores de dezesseis anos, salvo na condição de aprendiz, a partir de quatorze anos".

Neste mesmo viés, o Estatuto da Criança e do Adolescente (ECA) - Lei 8.069/1990 dedica todo o capítulo $\mathrm{V}$ para tratar da temática, enfatizando, no artigo 60 que "É proibido qualquer trabalho a menores de quatorze anos de idade, salvo na condição de aprendiz". Estabelece ainda que a profissionalização e proteção no trabalho devem ocorrer levando-se em conta a condição peculiar de pessoa em desenvolvimento e que a capacitação seja adequada ao mercado de trabalho.

O Estatuto sinaliza, em linhas gerais, a forma como deve ser a profissionalização dos adolescentes e sua entrada no mercado de trabalho, porém o detalhamento e a forma como todo o processo deve acontecer precisariam ser estabelecidos por meio de legislação própria, abrangendo todos os aspectos necessários para proteção desses adolescentes. Assim, em 19/12/2000 foi sancionada a Lei 10.097, conhecida como Lei da Aprendizagem. Essa lei altera os artigos 402, 403, 428, 429, 430, 431, 432 e 433 da CLT. Além disso, revoga o artigo 80, o parágrafo primeiro do artigo 405 e os artigos 436 e 437 da CLT. 
Com a promulgação da Lei de Aprendizagem, esclarecem-se muitas dúvidas que ainda existiam sobre a contratação de aprendizes, pois ela já inicia definindo a faixa etária para ser considerado aprendiz, ou seja, ter entre 14 a 18 anos $^{3}$, ao mesmo tempo em que proíbe o trabalho abaixo desta idade; caracteriza o que é o contrato de aprendizagem; obriga a matrícula e permanência desses adolescentes na escola; estabelece a remuneração devida aos aprendizes; as condições necessárias para a realização desse trabalho, que não podem ser prejudiciais à sua formação, bem como a carga horária diária de trabalho; fixa o percentual mínimo de $5 \%$ e máximo de $15 \%$ para as empresas na contratação dos aprendizes; estabelece direitos trabalhistas e previdenciários; as possiblidades de extinção do contrato de trabalho; trata das entidades habilitadas para ministrarem os cursos de aprendizagem.

A lei 10.097/2000 é considerada pelos autores da área da infância e adolescência como um grande avanço no sentido de garantir a formação profissional e a proteção de adolescentes e jovens no mundo do trabalho, principalmente dos filhos da classe operária.

Em 1으 de dezembro de 2005 foi publicado o Decreto № 5.598 que regulamentou a contratação de aprendizes sob diversos aspectos ${ }^{4}$. O Decreto inicia conceituando em seu art. $2 .^{\circ}$ que "aprendiz é o maior de quatorze anos e menor de vinte e quatro anos que celebra contrato de aprendizagem, nos termos do art. 428 da Consolidação das Leis do Trabalho - CLT".

Essas legislações são importantes no sentido de combater o trabalho infantil ao mesmo tempo em que estabelecem normativas para a contratação de adolescentes e jovens, como afirma Digiácomo e Digiácomo (2013, p.79):

Estabelecendo, dentre outras, a definição e os requisitos de validade do contrato de aprendizagem; os aspectos da formação técnico-profissional e das entidades qualificadas em formação técnico-profissional metódica; os direitos trabalhistas, as obrigações acessórias e a obrigatoriedade da concessão de certificado de qualificação profissional da aprendizagem, ao término do programa respectivo. Nem todas as atividades comportam a aprendizagem, mas sim apenas aquelas que, como mencionado no dispositivo, demandam a formação técnico-profissional (...). Pressupõe a existência de um curso ou programa de aprendizagem que evidencie seu caráter educativo-profissionalizante, em detrimento da produção.

Nesse sentido Saviani (2007, p. 155) afirma que:

É o trabalho que define a essência humana. Isso significa que não é possível ao homem viver sem trabalhar. Já que o homem não tem sua existência garantida pela natureza, sem agir sobre ela, transformando-a e adequando-a às suas necessidades, o homem perece. Daí o adágio: ninguém pode viver sem trabalhar.

Simões (2010) faz considerações importantes sobre as transformações que vem ocorrendo no processo de produção da sociedade e que influenciam tanto a educação quanto a formação profissional, principalmente dos "jovens pobres", que

\footnotetext{
${ }^{3}$ A faixa etária foi modificada posteriormente para 24 anos por meio do Decreto 5.598/2005.

${ }^{4}$ Esse decreto foi revogado em 2018 e substituído pelo Decreto 9.579 , de 22 de novembro de 2018. 
precisam se inserir no mundo do trabalho, mesmo que de maneira precária e informal. Desta forma, o autor continua:

\begin{abstract}
Colaborar com a construção de uma identidade profissional dos jovens trabalhadores pode representar uma estratégia positiva nas múltiplas possibilidades e interdições para suas transições à vida adulta. (...) Novos significados em relação ao trabalho são construídos pelos jovens ante a intensidade com que foram tocados pela incerteza e o desemprego juvenil. O trabalho aparece muitas vezes como uma referência central entre as opiniões, atitudes, expectativas e preocupações dos jovens e com significados diversos no imaginário juvenil, seja como valor, necessidade, direito ou mesmo como busca de aquisição de espaço e autonomia familiar e poder de consumo (SIMÕES, 2010, p. 99; 105).
\end{abstract}

Essa relação do trabalho com o desenvolvimento do jovem se torna ainda mais complexa quando consideramos o cenário de desigualdade no Brasil, que é um país considerado extremamente desigual, tanto que Oliveira (2013) usa a imagem de um ornitorrinco para descrever a sociedade brasileira, onde é possível encontrar, numa mesma cidade, diferenças descomunais, de desigualdade social e pobreza extrema, que segundo ele, não são produtos do atraso, como defendido muito tempo pelo senso comum, mas são conjunturais do capitalismo gerado no Brasil.

Reflexo também desse sistema é o desemprego, que de acordo com Oliveira (2013) não é uma fatalidade, é conjuntural e agudiza ainda mais a exclusão social. Dados da Pesquisa Nacional por Amostra de Domicílios Contínua (PNAD Contínua), divulgada em 31/01/2019 pelo Instituto Brasileiro de Geografia e Estatística (IBGE), aponta que cerca de 12,8 milhões de pessoas se encontravam desempregadas em 2018, sendo que a taxa de informalidade se mostrou a mais elevada desde o ano de 2012, revelando que o número de empregados sem carteira de trabalho chegou a 11,2 milhões. Sob esse aspecto Simões (2010, p. 105) aponta:

\begin{abstract}
A desigualdade econômica que caracteriza nosso país frustra a população, principalmente seus jovens, que precisam enfrentar a crise e inventar possibilidades de sucesso profissional: as chances de trabalho são escassas, assim a educação profissional entra como uma estratégia de enfrentamento da realidade no qual vemos estatísticas indicativas de queda no número de postos de trabalho regidos pelas leis trabalhistas, com 0 aumento concomitante do número de trabalhos temporários, sem direito às conquistas historicamente realizadas pelos trabalhadores. É assustador o número de famílias sobrevivendo do trabalho informal.
\end{abstract}

Ramos (2007), também sinaliza que diante das características históricas da sociedade brasileira de exploração dos trabalhadores, os filhos da classe trabalhadora não podem esperar concluir a educação básica ou o ensino superior para ir à busca de trabalho.

Sendo assim, a aprendizagem profissional é uma das alternativas encontradas pelos filhos da classe trabalhadora para se inserir no mundo do trabalho de forma protegida e com os direitos trabalhistas e previdenciários garantidos. Entretanto, a concepção de aprendizagem que norteia este trabalho é uma concepção mais ampla do que uma mera preparação para o mercado de trabalho (trabalho alienado), fundamentada no conceito de omnilateralidade de Marx, de formação do ser humano para a vida e não apenas para executar atividades profissionais impostas pelo mercado. 


\subsection{Caracterização da aprendizagem profissional à luz da legislação}

A aprendizagem profissional esteve historicamente vinculada ao Sistema $S^{5}$, até a aprovação da Lei 10.097/2000 que abriu possibilidades para que outras entidades voltadas à formação profissional pudessem ministrar os cursos de aprendizagem e o encaminhamento/acompanhamento dos adolescentes e jovens ao mundo do trabalho. A partir dessa abertura, muitas organizações da sociedade civil passaram a ofertar programas de aprendizagem, ampliando as possibilidades para que mais adolescentes e jovens pudessem ser atendidos.

O Manual da Aprendizagem do Ministério do Trabalho (2014, p. 13) define a aprendizagem como:

O instituto destinado à formação técnico-profissional metódica de adolescentes e jovens, desenvolvida por meio de atividades teóricas e práticas e que são organizadas em tarefas de complexidade progressiva. Tais atividades são implementadas por meio de um contrato de aprendizagem, com base em programas organizados e desenvolvidos sob a orientação e responsabilidade de entidades habilitadas.

Em 2005 foi publicado o Decreto n.- 5.598/2005 que regulamenta a contratação de aprendizes e caracteriza a faixa etária para aprendizes, que é entre 14 anos e 24 anos. Ressalta-se que aos aprendizes portadores de deficiência não se aplica a idade máxima. Esse decreto foi revogado em 2018 pelo presidente da República Michel Temer, o qual publicou o Decreto 9.579, que "Consolida atos normativos editados pelo Poder Executivo federal que dispõem sobre a temática do lactente, da criança e do adolescente e do aprendiz, e sobre o Conselho Nacional dos Direitos da Criança e do Adolescente, o Fundo Nacional para a Criança e o Adolescente e os programas federais da criança e do adolescente". Entretanto, o conteúdo do Decreto de 2005 não foi alterado, o objetivo do novo decreto foi consolidar matérias que antes eram tratadas via diferentes decretos relacionados à temática da criança e do adolescente, reunindo-os em um único documento; permanecendo desta forma, o que preconizava o Decreto de 2005. Demais espécies normativas (como leis) não foram atingidas.

Como o novo Decreto dispõe sobre outras legislações referentes à criança $e$ ao adolescente, destacamos que a aprendizagem profissional está sendo tratada no Capítulo V - Do Direito à Profissionalização, a partir da Seção II, artigo 43, até o artigo 75.

Feita essa ressalva, destaca-se que o artigo 45 do Decreto 9.579/2018 prevê que para a efetivação da aprendizagem, é necessário firmar um contrato de aprendizagem, por prazo determinado, não superior a dois anos, entre a instituição que ministra o curso de aprendizagem, o aluno ou seu responsável, caso ainda não tenha 18 anos completos, e a empresa contratante.

Além do contrato de aprendizagem, é obrigatória a anotação em carteira de trabalho; é exigida comprovação de matrícula e frequência do aprendiz à escola, bem como sua inscrição em programas de aprendizagem ministrados por entidades qualificadas, oferecendo uma formação técnico-profissional metódica, ou seja, que envolva tarefas de complexidade progressiva desenvolvidas no ambiente de

\footnotetext{
${ }^{5}$ SENAI, SESI, SENAC, SESC, SENAR, 
trabalho, respeitando os planos de cursos e oportunizando novos aprendizados aos adolescentes e jovens matriculados.

Tanto a lei $10.097 / 2000$ quanto o Decreto 9.579/2018 estabelecem a obrigatoriedade para estabelecimentos de qualquer natureza, de contratarem aprendizes, num percentual equivalente a 5\%, no mínimo, e 15\%, no máximo, do seu quadro funcional, cujas funções demandem formação profissional independentes de serem atividades proibidas para menores de 18 anos. Estão dispensadas da contração de aprendizes, segundo o artigo 56 do Decreto, as microempresas e empresas de pequeno porte e as organizações não governamentais que tenham por finalidade a educação profissional.

Neste aspecto da obrigatoriedade de contratação de aprendizes, algumas empresas encontram dificuldades para cumprir a cota determinada, pois exercem atividades consideradas insalubres ou periculosas e mesmo assim, precisam encontrar alternativas para contratar aprendizes. O artigo 66 do Decreto 9.579/2018 prevê que, mediante autorização do Ministério da Economia, essas atividades práticas poderão ser desenvolvidas na própria instituição que ministra o programa de aprendizagem; em órgãos públicos ou em unidades do sistema nacional de atendimento socioeducativo, mediante assinatura de termo de compromisso com 0 Ministério da Economia. Nestes casos específicos, o parágrafo 5. do artigo 66 estipula que a seleção dos aprendizes deverá ser feita por meio do cadastro público de emprego e devem ser priorizados:

\begin{abstract}
I - adolescentes egressos do sistema socioeducativo ou em cumprimento de medidas socioeducativas; II - jovens em cumprimento de pena no sistema prisional; III - jovens e adolescentes cujas famílias sejam beneficiárias de programas de transferência de renda; IV - jovens e adolescentes em situação de acolhimento institucional; $\mathrm{V}$ - jovens e adolescentes egressos do trabalho infantil; VI - jovens e adolescentes com deficiência; VII - jovens e adolescentes matriculados em instituição de ensino da rede pública, em nível fundamental, médio regular ou médio técnico, incluída a modalidade de Educação de Jovens e Adultos; e VIII - jovens desempregados e com ensino fundamental ou médio concluído em instituição de ensino da rede pública. (BRASIL, 2018).
\end{abstract}

Quanto à jornada de trabalho dos aprendizes, o artigo 60 estipula que não pode exceder 6 horas diárias e nem pode haver a prorrogação e a compensação da jornada. Caso o aprendiz já tenha concluído o ensino médio, a carga horária pode ser de até 8 horas, sendo computadas as horas dispensadas à parte teórica e à parte prática.

O artigo 59 estabelece que o aprendiz tem direito ao salário mínimo hora, exceto, se houver condição mais favorável, definido em convenções coletivas, ou pisos regionais.

Aos aprendizes são garantidos os direitos trabalhistas e previdenciários, (férias, 13. salário, vale-transporte, entre outros) com ressalva ao FGTS, cujo recolhimento é de $2 \%$ do salário recebido, conforme artigo segundo da Lei 10.097/2000. O artigo 68 do Decreto 9.579/2018 ainda estabelece que as férias dos aprendizes deverão coincidir com o período de férias escolares.

O artigo 71 do Decreto prevê as hipóteses de extinção do contrato de aprendizagem, que se dá quando o aprendiz completar 24 anos ou antes, mediante as seguintes situações: I- Desempenho insuficiente ou inadaptação do aprendiz; IIFalta disciplinar grave; III- Ausência injustificada à escola, que implique perda do ano letivo; IV- A pedido do aprendiz. 
O artigo 74 do Decreto prevê que após a conclusão do programa de aprendizagem será fornecido certificado de qualificação profissional, contendo informações referentes ao título e perfil profissional da ocupação para a qual o aprendiz foi qualificado.

O artigo 32 do Decreto 5.598/2005, estabeleceu que o Ministério do Trabalho e Emprego tem a competência de organizar o cadastro nacional das entidades interessadas em ministrar programas de aprendizagem profissional, além de definir diretrizes entre conteúdos e duração dos programas de aprendizagem, tendo como intuito a garantia da qualidade técnico-profissional ${ }^{6}$.

Diante disso, em 23/04/2012, o Ministério do Trabalho e Emprego publicou a

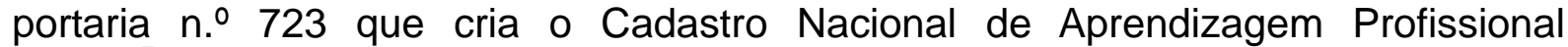
$\left(\mathrm{CNAP}^{7}\right)$, destinado ao cadastramento das entidades qualificadas em formação técnico profissional metódica definidas no artigo 8.ำ do Decreto 5.598 de 2005.

Desta forma, todas as entidades interessadas em ministrar programas de aprendizagem profissional devem fazer o cadastro de acordo com as normas estabelecidas na referida portaria. $O$ cadastro deve ser feito no portal: http://www.juventudeweb.mte.gov.br/. Com a alteração da Portaria 723/2012 em 2018, por meio da Portaria MTB 634/2018, estabeleceu-se que o cadastramento deverá ser feito por meio do sistema Mais Aprendiz www.maisaprendiz.mte.gov.br, o qual até o dia 06/04/2019 ainda não estava funcionando.

O cadastro abordado na Portaria prevê uma padronização mínima de exigências para os programas, tais como: matriz curricular, infraestrutura física, recursos humanos, mecanismos de acompanhamento e avaliação dos programas, entre outros.

O artigo 5. da Portaria n 723 prevê que para o cadastramento dos programas de aprendizagem, as instituições deverão repassar algumas informações mínimas, tais como o público participante dos programas de aprendizagem, indicando a faixa etária; estrutura do programa de aprendizagem e sua duração total em horas, contendo a definição e ementa dos programas, a organização curricular em módulos, núcleos ou etapas; a carga horária teórica e prática da aprendizagem, atividades práticas que serão desenvolvidas no local da prática laboral; infraestrutura física, como equipamentos, instrumentos e instalações necessárias para as ações do programa, com adequação aos conteúdos, à duração e à quantidade e perfil dos participantes.

O mesmo artigo ainda aponta a necessidade de as entidades informarem a quantidade e a qualificação do pessoal técnico-docente e de apoio que estarão envolvidos no processo de formação dos aprendizes, inclusive responsáveis pelo acompanhamento tanto das atividades teóricas como das atividades práticas nas empresas.

Outra exigência definida no artigo $5 . .^{\circ}$ é que a instituição informe os mecanismos de acompanhamento e avaliação do programa de aprendizagem, devendo incluir nesse processo o aprendiz e a empresa em que ele está contratado. Esse acompanhamento é de extrema importância, principalmente para evitar que ocorra o desligamento antecipado de aprendizes das empresas, mesmo em casos em que a legislação permite. A partir do momento que existe um acompanhamento

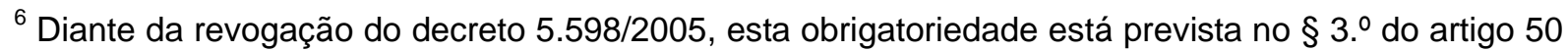
do Decreto 9.579/2018. Com a extinção do Ministério do Trabalho, essa atribuição está a cargo do Ministério da Economia.

${ }^{7}$ Essa portaria teve alguns artigos alterados pela Portaria 634 de 09 de agosto de 2018, as quais já foram consideradas na elaboração deste trabalho.
} 
constante dos adolescentes e jovens é possível atuar na orientação, tanto do aprendiz contratado quanto da empresa.

A legislação atual direcionada à aprendizagem orienta que as instituições formadoras prestem um atendimento de qualidade aos adolescentes e jovens inseridos nos seus programas de aprendizagem; sendo necessário 0 acompanhamento que inclua a verificação das atividades que estão sendo desenvolvidas dentro das empresas; as condições de trabalho; se os direitos trabalhistas e previdenciários estão sendo cumpridos; se estão desenvolvendo atividades de acordo com a formação teórica que recebem nos cursos; se está sendo respeitada sua condição peculiar de desenvolvimento, conforme previsto no Estatuto da Criança e do Adolescente.

Embora a fiscalização seja uma atribuição do Ministério da Economia, enquanto órgão fiscalizador das questões trabalhistas, a equipe técnica das instituições que ministram os cursos de aprendizagem precisa estar atenta e prestando todas as orientações necessárias às empresas e aos aprendizes, para que seus direitos sejam respeitados.

A partir da padronização e fiscalização propostas pela legislação da aprendizagem, busca-se evitar que os adolescentes e jovens sejam explorados pelas empresas como mão de obra barata, ou para substituir outros funcionários demitidos para redução de custos, uma vez que o papel do aprendiz não é assumir as responsabilidades de outro funcionário e sim de aprender com ele.

O artigo 5.. ainda prevê no seu inciso VIII que as entidades informem, quando do cadastramento de seus programas de aprendizagem "os mecanismos para propiciar a inserção dos aprendizes no mercado de trabalho após o término do contrato de aprendizagem". Esse aspecto se constitui num desafio para as entidades que trabalham com os aprendizes, pois a grande maioria não tem condições de atuar com os egressos de seus programas, seja por questões financeiras ou mesmo por falta de pessoal que se dedique a esse grupo que, após sair dos programas, muitas vezes não consegue inserção no mercado de trabalho.

O artigo 8. trata da elaboração dos programas de aprendizagem, os quais devem ser de acordo com o Catálogo Nacional de Programas de Aprendizagem Profissional (CONAP). Detalhado no Anexo I da Portaria 723/2012, o CONAP apresenta as orientações para as entidades elaborarem seus programas de aprendizagem. Baseado na Classificação Brasileira de Ocupações, especifica a carga horária total dos cursos, as atividades que serão desenvolvidas pelo profissional, além de estabelecer a idade e a escolaridade necessárias para o exercício de cada função ${ }^{8}$.

O CONAP norteia, portanto, as entidades para a elaboração dos seus programas de aprendizagem que podem ser de Nível de Formação Inicial e Continuada ou de Nível Técnico Médio. Ressaltando que os de nível técnico médio serão reconhecidos como cursos de aprendizagem "quando ofertados por instituições de ensino devidamente regularizadas perante o respectivo órgão competente do sistema de ensino e validados" (Art. 12 da Portaria 723/2012), devendo também atender aos outros requisitos dispostos nas legislações sobre a Aprendizagem Profissional.

8 O Anexo I na sua íntegra se encontra disponível no seguinte endereço eletrônico: http://trabalho.gov.br/aprendizagem. 
A formação teórica segue as diretrizes estabelecidas no Catálogo Nacional de Cursos Técnicos, instituído pela Resolução no 3, de 9 de julho de 2008 da Câmara de Educação Básica do Conselho Nacional de Educação, devendo ser acrescidas das horas práticas (CONAP, p. 4). (BRASIL, 2012)

As instituições que ofertam os cursos em nível de Formação Inicial e Continuada devem se adequar ao CONAP e seguir algumas diretrizes gerais e curriculares previstas no artigo 10 da Portaria 723/2012, tais como: A qualificação social e profissional adequada às demandas e diversidades dos adolescentes; Contribuição para a elevação do nível de escolaridade do aprendiz; Articulação de esforços nas áreas de educação, do trabalho e emprego, do esporte e lazer, da cultura e da ciência e tecnologia e assistência social (BRASIL, 2012).

O Parágrafo primeiro do artigo 10 da Portaria 723/2012 traz uma abordagem sobre as atividades teóricas e práticas dos cursos de aprendizagem que "devem ser pedagogicamente articuladas entre si sob a forma de itinerários formativos, com complexidade progressiva possibilitando ao aprendiz o desenvolvimento de sua cidadania e a compreensão das características do mundo do trabalho". Para tanto, estabelece minimamente os conteúdos a serem trabalhados nos programas de aprendizagem.

A portaria $723 / 2012$, no seu artigo 14 , aborda outra possibilidade dentro dos programas de aprendizagem que são os cursos na modalidade de Educação à Distância (EAD), autorizados mediante aprovação pelo Ministério do Trabalho9. Esses cursos também deverão ser cadastrados no CNAP e serão permitidos em locais em que:

I - o potencial de contração de aprendizes no município seja inferior a 25 no setor econômico (comércio, serviços, indústria, agricultura e transporte, entre outros); II - sua implantação imediata não seja possível em razão de inexistência de estrutura educacional adequada para a aprendizagem. (BRASIL, 2012).

A modalidade $E A D^{10}$ visa ofertar cursos de aprendizagem nas cidades de pequeno porte em que a necessidade de contratação de aprendizes por parte das empresas não justifique a formação de uma turma na modalidade presencial. $O$ Ministério do Trabalho estabeleceu algumas diretrizes para a oferta nessa modalidade, que são extremamente importantes, principalmente no sentido de evitar a precarização dos cursos e não deixar os aprendizes expostos a situações de violação de direitos, por falta de acompanhamento e fiscalização. Dentre essas diretrizes, que estão no Anexo II da Portaria 723, destacam-se:

Os projetos dos cursos deverão conter: a proposta pedagógica do curso, a descrição das soluções tecnológicas de apoio ao processo de ensino aprendizagem, a descrição dos conteúdos e as mídias a serem utilizadas, a descrição dos processos da gestão do conhecimento com a definição das atribuições de cada função envolvida (Gestores, Coordenadores, Professores, Tutores e outros) (Anexo II p. 1). (BRASIL, 2012).

\footnotetext{
${ }^{9} \mathrm{O}$ presidente eleito Jair Bolsonaro criou o Ministério da Economia, e extinguiu o Ministério do Trabalho, o qual passou a ser uma Secretaria dentro do novo ministério.

${ }^{10}$ O Anexo II da Portaria 723/2012, estabelece os referenciais para os cursos na modalidade EAD: http://www.trabalho.gov.br/images/Documentos/Aprendizagem/Anexoll Referenciais para cursosadis tancia.pdf
} 
O anexo II ainda prevê outras exigências que devem ser cumpridas pelas instituições que optarem pela execução de cursos de aprendizagem à distância, englobando o material didático a ser disponibilizado aos alunos; a contratação de profissionais com formação específica na área do curso; a disponibilização do calendário de atividades que serão realizadas na plataforma EAD utilizada pela instituição, de modo a permitir o acompanhamento pelos órgãos fiscalizadores; entre outras.

Tanto na modalidade EAD, como na presencial, deve-se respeitar as condições de pessoa em desenvolvimento, conforme prevê o Estatuto da Criança e do Adolescente, oportunizando a esse público o acesso e permanência à escola, programa de aprendizagem de qualidade, remuneração digna com a função a ser desempenhada, proibição da realização de trabalhos em locais perigosos ou insalubres, respeito aos direitos trabalhistas e previdenciários, além de uma formação não apenas técnica, mas também humana e geral.

Os adolescentes e jovens que buscam os cursos de aprendizagem têm uma expectativa de conseguirem o primeiro emprego, com registro em carteira, melhorias em suas condições socioeconômicas, conforme aponta Simões (2010, p. 105):

\begin{abstract}
O trabalho aparece, muitas vezes, como uma referência central entre as opiniões, atitudes, expectativas e preocupações dos jovens e com significados diversos no imaginário juvenil, seja como valor, necessidade, direito ou mesmo como busca de aquisição de espaço de autonomia familiar e poder de consumo.
\end{abstract}

Ressalta-se ainda a opinião de Ramos (2007), que afirma que o trabalho não é somente uma prática econômica de venda da força de trabalho para subsistência, não é apenas emprego, é por meio dele que os homens se constituem enquanto seres humanos, "trabalho é produção, criação, realização humanas. O trabalho é a primeira mediação entre o homem e a realidade social" (RAMOS, 2007, p. 3).

Nesse sentido, a aprendizagem profissional pode oportunizar essas conquistas para os adolescentes e jovens inseridos nos cursos ofertados pelas diversas entidades no Brasil.

Apresentaremos na sequência, alguns dados referentes ao ano de 2017, do Ministério do Trabalho (extinto pelo governo Bolsonaro), sobre a aprendizagem profissional no Brasil e no Paraná.

\title{
2.2 Levantamento situacional da aprendizagem profissional
}

A tabela 1 demonstra os dados relativos ao número de aprendizes contratados desde o ano de 2005 até o ano de 2017 no Brasil ${ }^{11}$.

Tabela 1 - Comparativo de contratação de aprendizes

\begin{tabular}{cc}
\hline Ano & Aprendizes Admitidos \\
\hline JAN DEZ 2017 & 386.791 \\
2017 & 388.773
\end{tabular}

\footnotetext{
${ }^{11}$ Ressalta-se que as tabelas foram retiradas do Boletim da Aprendizagem Profissional que estava disponível no site do Ministério do Trabalho e Emprego. Com a extinção do Ministério, as informações foram alocadas para o Ministério da Economia, entretanto, os Boletins não estão mais disponíveis. Foram feitas diversas tentativas de acesso, mas não foram localizados.
} 


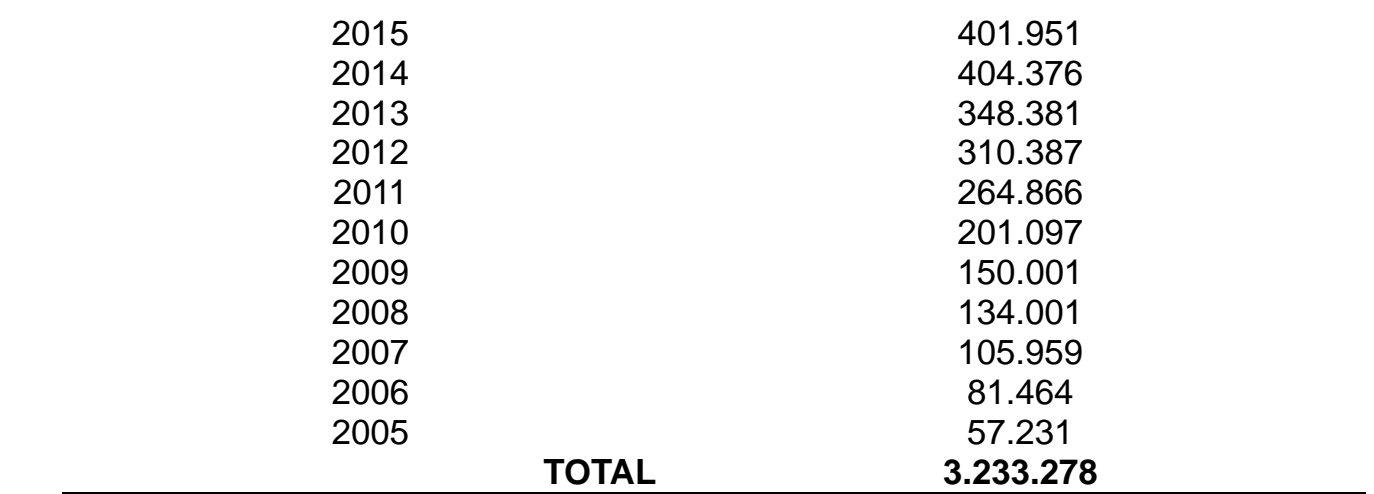

Fonte: Boletim da Aprendizagem Profissional

Percebe-se pelos dados da tabela 1 que houve um aumento significativo do número de contratações no decorrer dos anos, passando de 57.231 contratações em 2005, quando entrou em vigor o Decreto 5.598, para 386.791 em 2017. A partir de então, outras legislações surgiram, conforme já explanado neste artigo, e contribuíram para que a aprendizagem profissional se tornasse mais conhecida e também cumprida, por parte das empresas que precisam adequar-se à cota determinada por lei.

Por outro lado, um dado relevante expresso na tabela é que em 2014 o número de aprendizes contratados foi de 404.376, número que caiu nos anos seguintes, fechando 2017 com 17.585 admissões a menos que em 2014, ou seja, quase dezesseis mil adolescentes e jovens deixaram de ser inseridos nas empresas, pela redução das vagas, aumentando o número de desempregados no Brasil que no ano de 2017 foi de 12,3 milhões de pessoas, segundo dados da PNAD Contínua:

Apesar da queda na taxa de desocupação entre $03^{\circ}$ e $04^{\circ}$ trimestre, de $12,4 \%$ para $11,8 \%, 2017$ foi o pior ano para o mercado de trabalho no país desde 2012. Com uma taxa média de 12,7\%, o desemprego atingiu o maior nível da série histórica. Em relação a 2014, quando a taxa média de desocupação atingiu o menor patamar $(6,8 \%)$, a diferença foi de 5,9 p.p. (IBGE, 2018).

Essa redução na admissão de aprendizes também é reflexo da diminuição dos postos de trabalho no Brasil entre os anos citados, principalmente os postos de trabalho com carteira de trabalho assinada. Dados da mesma pesquisa do IBGE revelam que no ano de 2014 foram 36,6 milhões de postos de trabalho com registro formal e no ano de 2017 esse número caiu para 33,3 milhões, representando uma queda de 3,3 milhões nas vagas de trabalho formal.

Quando se perdem postos de trabalho formal, a tendência é aumentar a informalidade, pois as pessoas continuam tendo necessidades e precisam supri-las de alguma forma. Assim, de acordo com o IBGE, o aumento de pessoas trabalhando por conta própria foi de $6,5 \%$ em 2017, o que equivale a 1,3 milhões de pessoas atuando dessa forma.

Essa redução impacta negativamente na vida das pessoas, pois segundo Carmo, (1992, p.13) "estar desempregado não é estar com tempo livre para o lazer: os momentos de tensão, o sentimento de fracasso, de exclusão social, e a sensação de ser facilmente descartável afetam profundamente o desempregado".

Ainda segundo Wickert (1999), apud Leal (2010, p. 155), "trabalhar estruturalmente dá identidade, enquanto o desemprego gera sofrimento psíquico e coloca em risco a saúde mental". 
Ainda referente ao número de aprendizes contratados, a tabela 2 apresenta as contratações realizadas de janeiro a dezembro de 2017, bem como o potencial e o percentual de contratação nos estados brasileiros e no Distrito Federal.

Tabela 2 - Quantidade de Aprendizes Admitidos de janeiro a dezembro de 2017 e Potencial de Contratação

\begin{tabular}{|c|c|c|c|}
\hline 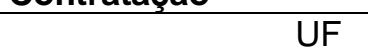 & Potencial & Admitidos & $\%$ \\
\hline Acre & 1.783 & 909 & 50,98 \\
\hline Alagoas & 8.303 & 2.590 & 31,19 \\
\hline Amapá & 1.393 & 843 & 60,52 \\
\hline Amazonas & 11.253 & 5.120 & 45,50 \\
\hline Bahia & 39.253 & 17.107 & 43,58 \\
\hline Ceará & 27.520 & 16.506 & 59,98 \\
\hline Distrito Federal & 18.636 & 7.540 & 40,46 \\
\hline Espírito Santo & 16.906 & 8.518 & 50,38 \\
\hline Goiás & 26.923 & 13.610 & 50,55 \\
\hline Maranhão & 10.731 & 3.263 & 30,41 \\
\hline Mato Grosso & 15.914 & 6.738 & 42,34 \\
\hline Mato Grosso do Sul & 12.882 & 3.712 & 28,82 \\
\hline Minas Gerais & 93.273 & 40.240 & 43,14 \\
\hline Pará & 17.999 & 7.315 & 40,64 \\
\hline Paraíba & 9.074 & 4.596 & 50,65 \\
\hline Paraná & 60.024 & 24.123 & 40,19 \\
\hline Pernambuco & 30.627 & 10.976 & 35,84 \\
\hline Piauí & 6.761 & 1.766 & 26,12 \\
\hline Rio de Janeiro & 82.609 & 35.038 & 42,47 \\
\hline Rio Grande do Norte & 9.365 & 4.253 & 45,41 \\
\hline Rio Grande do Sul & 65.244 & 32.314 & 49,53 \\
\hline Rondônia & 5.047 & 2.535 & 50,23 \\
\hline Roraima & 1.196 & 775 & 64,80 \\
\hline Santa Catarina & 49.605 & 23.197 & 46,76 \\
\hline São Paulo & 306.663 & 108.300 & 35,32 \\
\hline Sergipe & 6.819 & 3.347 & 35,32 \\
\hline Tocantins & 3.928 & 1.510 & 38,44 \\
\hline Total & 939.731 & 386.791 & 41,16 \\
\hline
\end{tabular}

Fonte: Boletim da Aprendizagem Profissional

Mesmo com a redução de postos de trabalho apontado na tabela 1, os dados da tabela 2 revelam que 386.791 aprendizes foram admitidos de janeiro a dezembro de 2017 , ou seja, $41,16 \%$ de um potencial de contratação ${ }^{12}$ que é de 939.731. Alguns estados mal chegam a contratar $1 / 3$ da demanda real e apenas 8 estados atingem um percentual acima de $50 \%$.

O estado do Paraná tem um potencial de contratação de 60.024 aprendizes, porém, apenas $24.123(40 \%)$ adolescentes e jovens foram admitidos em 2017, ficando ainda um contingente de 35.901 vagas sem preenchimento.

Segundo dados do IBGE, em 2010, o Paraná tinha 928.028 adolescentes e jovens na faixa etária de 15 a 19 anos e 900.869 jovens na faixa etária de 20 a 24 anos, que são o público alvo a ser contemplado pelas vagas de aprendizes, de acordo com a legislação. Somando-se o público nessas duas faixas etárias, tem-se 1.828.897 adolescentes e jovens no Paraná, e destes, 24.123 tiveram a

\footnotetext{
12 O potencial de contratação leva em consideração a cota obrigatória de aprendizes que cada empresa deveria contratar, de acordo com a Lei 10.097/2000 e suas alterações.
} 
oportunidade de participar de um curso de aprendizagem e ter uma experiência de trabalho protegido, com os direitos trabalhistas e previdenciários garantidos.

Ressalta-se que a aprendizagem profissional é uma das estratégias de combate ao trabalho infantil, que historicamente faz parte da sociedade brasileira, retirando de muitas crianças e adolescentes direitos fundamentais como o de ir para a escola, como revelam os dados do IBGE referente ao ano de 2016:

Em 2016, 1,8 milhões de crianças de 5 a 17 anos trabalhavam no Brasil. Mais da metade delas $(54,4 \%$ ou 998 mil), pelo menos, estavam em situação de trabalho infantil, ou porque tinham de 5 a 13 anos (190 mil pessoas), ou porque, apesar de terem de 14 a 17 anos, não possuíam o registro em carteira (808 mil) exigido pela legislação (IBGE, 2017).

Os dados do IBGE (2017) ainda revelam que no grupo composto por adolescentes de 14 a 17 anos que estavam ocupados em 2016 , apenas $79,5 \%$ estavam estudando. Os que estavam trabalhando e não estudavam recebiam rendimento maior do que os que trabalhavam e estudavam, provavelmente porque essas tinham mais tempo "livre" para dedicar-se ao trabalho, já que estavam fora da escola.

Desta forma, entende-se que a aprendizagem profissional pode contribuir para uma mudança desta realidade, mas são necessárias algumas intervenções para que um maior número de adolescentes e jovens sejam inseridos nos programas de aprendizagem, dentre elas a fiscalização por parte do ministério Público do Trabalho, junto às empresas que não estejam cumprindo a cota determinada pela legislação. Também se faz necessário que os empresários compreendam o papel social da Lei da Aprendizagem e da diferença que trará para os adolescentes/jovens aprendizes atendidos, principalmente para auxiliar no sustento de suas famílias.

Dentre as contratações realizadas no decorrer de 2017, a Tabela 3 apresenta informações das ocupações que tiveram os maiores índices de contratação no período de janeiro a dezembro de 2017 no Brasil.

Tabela 3 - Ocupações com maiores índices de contratação de JAN a DEZ de 2017: Aprendizes admitidos de JAN a DEZ 2017 por ocupação

\begin{tabular}{l|cc}
\hline CBO 2002 Ocupação & Aprendiz & $\%$ \\
\hline Auxiliar de Escritório, em Geral & 155.512 & 40,21 \\
Assistente Administrativo & 70.192 & 18,15 \\
Vendedor de Comércio Varejista & 21.261 & 5,50 \\
Repositor de Mercadorias & 20.535 & 5,31 \\
Mecânico de Manutenção de Maquinas, em Geral & 14.324 & 3,70 \\
Alimentador de Linha de Produção & 11.832 & 3,06 \\
Embalador, a Mão & 6.361 & 1,64 \\
Continuo & 4.605 & 1,19 \\
Trabalhador Polivalente da Confecção de Calçados & 4.035 & 1,04 \\
Ajustador Mecânico & 4.082 & 1,06 \\
Outros & 74.052 & 19,15 \\
& & 386.791 \\
\hline
\end{tabular}

Fonte: Boletim da Aprendizagem Profissional 
$\mathrm{Na}$ tabela 3 visualiza-se que as ocupações com maiores índices de contratações dos meses de janeiro a dezembro de 2017 e a que mais se destaca é a de Auxiliar de Escritório em Geral com 124.530 (40,04\%) contratações, seguida pela ocupação de Assistente Administrativo, com 54.556 (17,54\%) contratações. Somando-se os percentuais chega-se a $57,58 \%$ de aprendizes contatados para área administrativa, ou seja, mais da metade das vagas.

Esses dados permitem chegar a algumas conclusões, dentre elas a de que a maioria dos cursos ofertados está voltada para a área administrativa, talvez por ser a de menor risco para os aprendizes, já que a legislação prevê uma série de atividades que não podem ser executadas por adolescentes.

A área administrativa também se coloca com muitas oportunidades para a realização dos trabalhos dos aprendizes, permitindo que se adquiram conhecimentos diversos como financeiro, contábil, recursos humanos, treinamento e qualificação da equipe, atendimento ao público, entre outros. Esse conhecimento adquirido pelo aprendiz oportuniza sua entrada em outras empresas ao término do seu contrato de aprendizagem, caso ele não seja efetivado na mesma empresa, cumprindo assim também o papel da aprendizagem profissional de permanência desses jovens no mundo do trabalho.

A tabela 3 também coloca como última opção "outros", dando um percentual de contratação de 19,99\%, infelizmente esse dado não permite identificar em quais outras ocupações os aprendizes estão inseridos. Desta forma, percebe-se a necessidade de abertura de vagas para a aprendizagem profissional em outras funções, que não exponham os adolescentes a riscos, mas que também oportunizem outros tipos de conhecimento que não apenas na área administrativa, embora os cursos de aprendizagem sejam de uma formação inicial e que procure incentivar e possibilitar aos adolescentes e jovens a busca contínua pela educação e aperfeiçoamento profissional, e não fique apenas com o certificado de aprendizagem profissional.

\section{CONSIDERAÇÕES FINAIS}

O trabalho para adolescentes e jovens é questionado por diversos autores, pois nele se inserem principalmente os filhos da classe operária, uma vez que os filhos das elites seguem seus estudos rumo a cursos superiores, sem precisar trabalhar. Entretanto, como já demonstrado no presente artigo, os filhos da classe operária se veem obrigados a se inserir no mercado de trabalho, isso nem sempre é uma escolha deles, mas uma condição que a sociedade capitalista os impõe.

Diante dessa falta de opção, esses jovens precisam inserir-se profissionalmente no mundo do trabalho e a aprendizagem profissional possibilita essa inserção de maneira protegida, garantindo, desta forma, os direitos previstos na Constituição e no Estatuto da Criança e do Adolescente.

Josviak (2017, p. 69) assim se posiciona sobre a Aprendizagem Profissional:

Tem, positivamente contribuído para que muitos jovens sejam profissionalizados, acolhidos pela Família, Estado e Sociedade e resgatados da exclusão de que são vítimas, essencialmente porque promove necessariamente a profissionalização, garantindo-Ihes, a partir daí, outros direitos previstos no art. 227 da Constituição Federal Brasileira, quais sejam: direito ao lazer, a saúde, a alimentação, a educação, dentre outros. 
Entendemos que cursos de aprendizagem podem contribuir para um aspecto apontado por Ciavatta (2005, p. 17) a respeito da educação que permite a construção de identidade:

\begin{abstract}
A educação é uma instituição necessária para incorporar a população a todo tipo de transformação social, efetiva, que se pretenda. Se, como é sobejamente conhecido, a educação é incapaz de mudar a sociedade desigual em que vivemos, ela é uma porta relevante para compreensão dos fundamentos da desigualdade e para a geração de uma nova institucionalidade no país.
\end{abstract}

Temos a compreensão de que os cursos de aprendizagem não mudarão a estrutura da sociedade capitalista em que vivemos, nem tampouco acabarão com o desemprego estrutural, entretanto, podem trazer benefícios significativos para os adolescentes e jovens das classes populares, que necessitam do emprego para auxiliarem na manutenção financeira de suas famílias, contribuindo para a construção de sua identidade enquanto sujeitos e consequente melhoraria de sua autoestima.

Percebe-se também na legislação atual da aprendizagem profissional, conforme já descrito neste trabalho, uma preocupação com o adolescente e jovem trabalhador, entretanto, se faz necessária uma fiscalização do Ministério da Economia, Conselhos Municipais da Criança e do Adolescente e também um acompanhamento das entidades responsáveis pela aprendizagem profissional, para que esses adolescentes e jovens não sejam explorados, submetidos a trabalhos precarizados, insalubres, perigosos, ou mesmo em funções que não condizem com a formação teórica do curso que estão matriculados.

Existem ainda muitos desafios a serem superados para que a aprendizagem profissional alcance o objetivo de atender mais adolescentes e jovens, para cumprir seu papel social, principalmente o cumprimento da cota mínima de contratações prevista na legislação.

Por fim, destaca-se que as mudanças na legislação relacionada à aprendizagem trouxeram avanços significativos no número de oportunidades a jovens e adolescentes participantes dos programas de aprendizagem, considerando o aumento de contratações demonstrado nas tabelas já apresentadas, ressalvandose o período de queda deste número em função da redução de postos de trabalho. Entende-se, portanto, que numa sociedade capitalista, onde os interesses do capital se sobrepõem a todos os outros, é preciso o cumprimento do que a Lei 10.097/2000 impõe como obrigatoriedade e a fiscalização contínua que garanta que a prática dentro das empresas realmente contribua com o processo de formação dos jovens aprendizes.

\title{
REFERÊNCIAS
}

BRASIL. Presidência da República. Casa Civil. Constituição da República

Federativa do Brasil. Brasília, DF, 1988. Disponível em:

http://www.planalto.gov.br/ccivil 03/constituicao/constituicaocompilado.htm. Acesso em 02/11/2018.

\section{Lei no 8.069/1990 - Estatuto da Criança e do}

Adolescente. Brasília, DF, 1990. Disponível em: http://www.planalto.gov.br/ccivil 03/leis/L8069.htm. Acesso em: 02/11/2018. 
Decreto no 5.598/2005. Brasília. DF, 2005. Disponível em: http://www.planalto.gov.br/ccivil 03/ ato2004-2006/2005/decreto/d5598.htm. Acesso em: 02/11/2018.

Decreto no 9.579, de 22 de novembro de 2018.

Consolida atos normativos editados pelo Poder Executivo federal que dispõem sobre a temática do lactente, da criança e do adolescente e do aprendiz, e sobre 0 Conselho Nacional dos Direitos da Criança e do Adolescente, o Fundo Nacional para a Criança e o Adolescente e os programas federais da criança e do adolescente, e dá outras providências. Disponível em:

http://www.planalto.gov.br/ccivil 03/ Ato2015-2018/2018/Decreto/D9579.htm. Acesso em: 02/02/2019.

Lei n.o 12.435/2011 - Altera a Lei no 8.742, de 7 de dezembro de 1993, que dispõe sobre a organização da Assistência Social. Brasília, DF, 2011. Disponível em http://www.planalto.gov.br/ccivil 03/ ato20112014/2011/lei//12435.htm. Acesso em 10/11/2018.

Decreto-Lei no 5.452/1943. Brasília, DF, 1943. Disponível em: http://www.planalto.gov.br/ccivil 03/Decreto-Lei/Del5452.htm\#art437. Acesso em: 02/11/2018.

Portaria 634/2018. Brasília, DF, 2018. Disponível em: Disponível em: http://pesquisa.in.gov.br/imprensa/isp/visualiza/index.jsp?data=10/08/2018\&jornal=5 15\&pagina $=139 \&$ totalArquivos=185. Acesso em 10/03/2019.

Ministério do Trabalho e Emprego. Lei no. 10.097/2000 - Lei da Aprendizagem. Brasília, DF, 2000. Disponível em:

http://www.planalto.gov.br/ccivil 03/leis/L10097.htm. Acesso em: 02/11/2018.

Manual da Aprendizagem: O que é preciso saber para contratar o aprendiz. Brasília, DF, 2014. Disponível em:

http://www.trabalho.gov.br/images/Documentos/Aprendizagem/Manual da Aprendiz agem2017.pdf. Acesso em: 12/01/2019.

Boletim da Aprendizagem janeiro a setembro de 2017.

Brasília, DF, 2017. Disponível em: http://trabalho.gov.br/images/Documentos/boletimjan-a-set-2017.pdf. Acesso em: 10/01/2019.

Portaria 723/2012. Brasília, DF, 2012. Disponível em: http://www.trabalho.gov.br/images/Documentos/Aprendizagem/Portaria MTE 7232 012.pdf. Acesso em: 10/01/2019.

CARMO, P. S. do. A ideologia do trabalho. São Paulo: Moderna, 1992.

CIAVATTA, M. A formação integrada: a escola e o trabalho como lugares de memória e de identidade. In: Trabalho necessário. Ano 3. v. 3, n. 3. 2005. Disponível em: 
http://periodicos.uff.br/trabalhonecessario/article/view/6122/5087. Acesso em: 22/02/2019.

\section{DIGIÁCOMO, M. J; DIGIÁCOMO, I. A. Estatuto da Criança e do Adolescente} Anotado e Interpretado. Curitiba, SEDS, 2013.

IBGE. Instituto Brasileiro de Geografia e Estatística. PNAD Contínua. Rio de Janeiro, 2018. Disponível em: https://agenciadenoticias.ibge.gov.br/agencianoticias/2012-agencia-de-noticias/noticias/19759-desemprego-recua-em-dezembromas-taxa-media-do-ano-e-a-maior-desde-2012. Acesso em: 20/03/2019.

. Rio de Janeiro, 2019. Disponível em:

https://agenciadenoticias.ibge.gov.br/agencia-noticias/2012-agencia-denoticias/noticias/23867-desemprego-sobe-e-atinge-12-7-milhoes-de-pessoas-aposdois-trimestres-de-queda. Acesso em: 20/03/2019.

. Rio de Janeiro, 2019. Disponível em:

https://agenciadenoticias.ibge.gov.br/agencia-noticias/2012-agencia-denoticias/noticias/23652-desocupacao-cai-para-12-3-no-ano-com-recorde-depessoas-na-informalidade. Acesso em: 20/03/2019.

Rio de Janeiro, 2018. Disponível em

https://cidades.ibge.gov.br/brasil/pr/panorama. Acesso em: 20/03/2019.

. Rio de Janeiro, 2019. Disponível

em:https://cidades.ibge.gov.br/brasil/pr/pesquisa/23/25888?detalhes=true. Acesso em: 02/04/2019

. Rio de Janeiro, 2019. Disponível em:

https://agenciadenoticias.ibge.gov.br/agencia-sala-de-imprensa/2013-agencia-denoticias/releases/18383-pnad-continua-2016-brasil-tem-pelo-menos-998-milcriancas-trabalhando-em-desacordo-com-a-legislacao. Acesso em 02/04/2019.

JOSVIAK, M. et all (orgs). O Sinase e as Políticas Públicas para o Jovem em Conflito com a Lei: A aprendizagem profissional à luz dos Direitos Humanos e Fundamentais. In JOSVIAK, M. Aprendizagem Profissional e Direitos Humanos: O direito fundamental dos jovens à profissionalização. São Paulo: LTR, 2017.

KUENZER, A. (org.). Ensino Médio: Construindo uma proposta para os que vivem do trabalho. São Paulo: Cortez, 2000.

LEAL, M. C. O Estatuto da Criança e do Adolescente e a Lei de Diretrizes e Bases da Educação como marcos inovadores de políticas sociais. In: SALES, M. A. et al (orgs.). Política Social, Família e Juventude: uma questão de direitos. 6. ed. São Paulo: Cortez, 2010.

MANFREDI, S. M. Educação Profissional No Brasil: Atores e cenários ao longo da História. São Paulo: Paco Editorial, 2016. 
MOURA, D. H. Educação Básica e Educação Profissional e Tecnológica: dualidade histórica e perspectivas de Integração. Holos, Rio Grande do Norte; ano 23, v. 2, 2007. Disponível em:

http://www2.ifrn.edu.br/ojs/index.php/HOLOS/article/viewFile/11/110. Acesso em 12/01/2018. Acesso em: 22/10/2018.

Ensino médio e educação profissional: dualidade histórica e possibilidades de integração. In: MOLL, J. e colaboradores. Educação Profissional e Tecnológica no Brasil Contemporâneo: desafios, tensões e possibilidades. Porto Alegre: ArtMed, 2010.

OLIVEIRA, F. de. Crítica à razão dualista: o ornitorrinco. 1 ed. São Paulo: Boitempo, 2013.

SAVIANI, D. Trabalho e Educação: fundamentos ontológicos e históricos. Revista Brasileira de Educação v. 12 n. 34 jan./abr. 2007. Disponível em: http://www.scielo.br/pdf/rbedu/v12n34/a12v1234.pdf. Acesso em: 22/10/2018.

SIMÕES, C. A. Educação técnica e escolarização de jovens trabalhadores. In: MOLL. J. (org). Educação Profissional e Tecnológica no Brasil Contemporâneo: Desafios, tensões e possibilidades. Porto Alegre: Artmed, 2010, pp. 96-119. 